\title{
Evaluation of inhaled beta-2 agonist in management of transient tachypnea of the newborn
}

\author{
Ahmed A. Talaat, Maha M. A. Abohashish, Tarek M. Farid and Mohab M. Salah
}

\begin{abstract}
Background: Transient tachypnea of the newborn (TTN) is a common cause of early neonatal respiratory distress. It is due to delayed clearance of fetal lung fluid.

Aim: To evaluate the effect of inhaled salbutamol, a beta-2 adrenergic agonist ( $\beta 2 A A)$, in management of TTN and to detect any side effects as a result of using it

Methods: A total of 100 infants with TTN were randomly divided into two groups to receive either inhaled salbutamol (treatment group) or an equal volume of normal saline solution (placebo group) at the time of diagnosis. At enrollment (by the 6th hour), complete blood count, blood glucose, serum potassium (K+), arterial blood gasses, respiratory rate, heart rate, blood oxygen saturation $\left(\mathrm{O}_{2} \mathrm{Sat}\right)$, fraction of inspired oxygen $\left(\mathrm{FiO}_{2}\right)$, and $\Pi \mathrm{T}$ clinical score were determined for all patients. At 0.5, 1, and $4 \mathrm{~h}$ after drug administration, respiratory rate, heart rate, $\mathrm{O}_{2} \mathrm{Sat}, \mathrm{FiO}_{2}$, and the clinical $T \mathrm{TN}$ score were recorded. At $4 \mathrm{~h}$ after treatment, arterial blood gasses, serum $\mathrm{K}+$, and blood glucose levels were measured again. The duration of total respiratory support and the duration of hospitalization were recorded as well.

Results: No statistically significant differences existed between both groups in terms of gestational age, birth weight, gender, mode of delivery, Apgar score, or maternal risk factors. The duration of respiratory support and duration of hospitalization were significantly shorter in the treatment (salbutamol) group $(P<0.0005, P<0.0002$, respectively). In the treatment (salbutamol) group; the respiratory rate, $\mathrm{FiO}_{2}$ and $T \mathrm{TN}$ score were significantly lower after treatment $\left(P<0.0001, P<0.0000, P<0.0000\right.$, respectively). Also the $\mathrm{PaO}_{2}$ significantly increased $(P<0.0000)$ with significant improvement in $\mathrm{PH}(P<0.0001)$ and significant reduction in $\mathrm{PaCO}_{2}(P<0.03)$. However, there were no statistically significant differences in heart rates, serum $\mathrm{K}+$, or glucose levels after treatment.
\end{abstract}

Conclusion: Inhaled salbutamol, a $\beta 2 A A$, was effective in reducing the duration of respiratory support and hospitalization in $\Pi \mathrm{N}$, with no detected side effects.

Keywords: Newborn, Transient tachypnea, $\beta 2$-agonist, Salbutamol

\section{Introduction}

Transient tachypnea of the newborn (TTN) is the commonest cause of early neonatal respiratory distress. It is due to delayed clearance of the fluid present in the fetal lungs (Hjalmarson 1981; Aslan et al. 2008). At birth, the mature fetal lungs switch from active chloride (fluid) secretion which is important for its growth and development to

\footnotetext{
* Correspondence: atalaat62@gmail.com

Pediatric Department, National Research Centre, Cairo, Egypt
}

active sodium (fluid) absorption in response to the rise in circulating fetal catecholamines (Richardson et al. 2005). Catecholamines exert its effect on the beta adrenergic receptors in the alveolar cells resulting in an increase in epithelial $\mathrm{Na}+$-channels $(\mathrm{ENaC})$ and sodium-potassium adenosine triphosphatase ( $\mathrm{Na}+\mathrm{K}+-\mathrm{ATPase})$ activity (Barker and Oliver 2002). Failure of the switch from fluid secretion to fluid absorption by the fetal lung and an immaturity in the expression of the $\mathrm{ENaC}$ may play an important role in the development of TTN (Davies 2004). Stimulation of $\beta$ adrenergic receptors by beta- 2 adrenergic agonists ( $\beta 2 \mathrm{AA})$ 
upregulates alveolar epithelial $\mathrm{Na}+$ transport through increasing the activity of $\mathrm{ENaC}$ and $\mathrm{Na}+-\mathrm{K}+-\mathrm{ATPase}$ and protein abundance at the plasma membrane (Minakata et al. 1998; Mutlu et al. 2004). Previous studies on animal and human lungs pointed to a potential therapeutic role for B2AA in facilitating resorption of alveolar fluid (Sakuma et al. 1997; Frank et al. 2008). Although a self-limited condition that may resolve within $48-72 \mathrm{~h}$, tachypnea in TTN may be severe and persists, delaying initiation of feeding and increasing the duration of hospitalization (Moresco et al. 2016). The aim of our study was to evaluate the effect of inhaled salbutamol, a $\beta 2 \mathrm{AA}$, in management of TTN and to detect any side effects as a result of using it.

\section{Methods}

This is a multi-centric study conducted at the neonatal intensive care unit (NICU) of four hospitals (Al-Shorouk, Demashk, Magdy and AL-Safwa) during 2018-2019. A total of 100 infants with TTN were randomly divided into two groups to receive either inhaled salbutamol or an equal volume of normal saline solution placebo at the time of diagnosis. Informed consent was obtained from the parents, and the study protocol was approved by the National Research Centre Ethics Committee. Patients were eligible for enrolment if they were diagnosed with TTN and are $<6 \mathrm{~h}$ old. The diagnoses of TTN was according to the criteria of Rawlings and Smith (1984) on the basis of clinical and radiological findings of (1) onset of tachypnea within $6 \mathrm{~h}$ after birth; (2) persistence of tachypnea for at least $12 \mathrm{~h}$; (3) chest radiograph indicating at least one of the following: prominent central vascular markings, widened inter-lobar fissure of pleural fluid, symmetrical perihilar congestion, hyperaeration as evidenced by flattening and depression of the diaphragmatic domes or increased anteroposterior diameter, or both; and (4) exclusion of other known respiratory disorders (respiratory distress syndrome, pneumonitis, meconium aspiration syndrome), and non-respiratory disorders (congenital heart diseases, polycythemia, hypoglycemia) likely to cause tachypnea.

At enrollment (by the 6th hour), complete blood count, blood glucose and $\mathrm{K}+$, arterial blood gasses, respiratory rate, heart rate, blood oxygen saturation $\left(\mathrm{O}_{2}\right.$ Sat), fraction of inspired oxygen $\left(\mathrm{FiO}_{2}\right)$, and TTN clinical score (Table 1) were determined for all patients.

Patients were randomized in a blinded manner to receive one nebulized dose of either $0.9 \%$ normal saline solution (group I, placebo), or a solution of salbutamol (group II, treatment) in $0.9 \%$ saline solution at a standard dose of $0.15 \mathrm{mg} / \mathrm{kg}$. At $0.5,1$, and $4 \mathrm{~h}$ after drug administration, respiratory rate, heart rate, $\mathrm{O}_{2} \mathrm{Sat}, \mathrm{FiO}_{2}$, and the clinical TTN score were recorded. At $4 \mathrm{~h}$ after treatment, arterial blood gasses, serum $\mathrm{K}+$, and blood glucose levels were measured again. The duration of total respiratory support and the duration of hospitalization were recorded as well.
Table 1 Clinical TTN score

\begin{tabular}{lllll}
\hline Score & 0 point & 1 point & 2 points & 3 points \\
\hline $\begin{array}{l}\text { Expiratory grunting } \\
\text { Supraclavicular }\end{array}$ & None & Intermittent & Continuous & - \\
retraction & Mild & Moderate & Severe \\
Subcostal retraction & None & Mild & Moderate & Severe \\
Cyanosis & None & At extremities & Central & - \\
Nasal flaring & None & mild & Moderate & Severe \\
\hline
\end{tabular}

\section{Statistical analysis}

Data analysis was carried out using the standard computer program Statistical Package for the Social Sciences (SPSS) for Windows, release 17.0 (SPSS Inc., USA). All numeric variables were expressed as mean \pm standard deviation (SD). The intergroup comparisons were performed by using an independent-sample $t$ test and a one-way analysis of variance and Chi-Square tests for categorical variables. For all tests, a $P$ value of less than 0.05 was considered significant.

\section{Results}

The study included a total of 100 neonates diagnosed with TTN who were randomly divided into two groups.

Table 2 Demographic data of study groups and maternal risk factors

\begin{tabular}{|c|c|c|c|}
\hline Variables & $\begin{array}{l}\text { Group I } \\
\text { (saline) }\end{array}$ & $\begin{array}{l}\text { Group II } \\
\text { (salbutamol) }\end{array}$ & $P$ value \\
\hline Number & 46 & 54 & \\
\hline $\operatorname{Sex}(M / F)$ & 27/19 & $32 / 22$ & 0.995 \\
\hline $\begin{array}{l}\text { Gestational age } \\
\text { (weeks } \pm \text { SD) }\end{array}$ & $36.85 \pm 1.57$ & $36.73 \pm 1.66$ & 0.504 \\
\hline $\begin{array}{l}\text { Birth weight } \\
(\mathrm{gm} \pm \mathrm{SD})\end{array}$ & $2883.15 \pm 437.94$ & $2825.87 \pm 414.61$ & 0.731 \\
\hline Hemoglobin (g/dl) & $15.33 \pm 1.49$ & $15.12 \pm 1.55$ & 0.481 \\
\hline $\begin{array}{l}\text { Weight blood } \\
\text { cell count }\left(/ \mathrm{mm}^{3}\right)\end{array}$ & $16,283 \pm 3141$ & $16,591 \pm 1884$ & 0.446 \\
\hline $\begin{array}{l}\text { Elective cesarean } \\
\text { section/NVD }\end{array}$ & $27 / 19$ & $31 / 23$ & 0.897 \\
\hline $\begin{array}{l}\text { Apgar score } \\
(5 \text { th } \min )^{*}\end{array}$ & 9 & 9 & 0.27 \\
\hline $\begin{array}{l}\text { Oxygen } \\
\text { saturation (\%) }\end{array}$ & $88.7 \pm 3.98$ & $89.96 \pm 3.93$ & 0.15 \\
\hline $\begin{array}{l}\text { Duration of } \\
\text { respiratory } \\
\text { support (h) }\end{array}$ & $61.43 \pm 16.81$ & $49.17 \pm 15.86$ & 0.0005 \\
\hline $\begin{array}{l}\text { Duration of } \\
\text { hospitalization (days) }\end{array}$ & $4.76 \pm 1.14$ & $3.89 \pm 1.08$ & 0.0002 \\
\hline \multicolumn{4}{|l|}{ Maternal risk factors } \\
\hline Maternal age & $29.12 \pm 4.45$ & $28.53 \pm 4.78$ & 0.499 \\
\hline Maternal diabetes & 3 & 5 & \\
\hline PROM & 3 & 2 & \\
\hline
\end{tabular}

*Median. PROM premature rupture of membrane 
Table 3 Comparison of data before and $4 \mathrm{~h}$ after treatment among study groups

\begin{tabular}{|c|c|c|c|c|c|c|}
\hline \multirow[t]{2}{*}{ Variable } & \multicolumn{2}{|l|}{ Group I (saline) } & \multirow{2}{*}{$\begin{array}{l}P \\
\text { value }\end{array}$} & \multicolumn{2}{|c|}{ Group II (salbutamol) } & \multirow[t]{2}{*}{$P$ value } \\
\hline & Before & After & & Before & After & \\
\hline Respiratory rate (breath/min) & $74.36 \pm 8.08$ & $71.47 \pm 8.15$ & 0.09 & $72.11 \pm 7.56$ & $62.59 \pm 7.43$ & 0.0001 \\
\hline Heart rate (beats/min) & $148.32 \pm 11.52$ & $146.33 \pm 22.28$ & 0.17 & $144.78 \pm 10.34$ & $142.72 \pm 10.25$ & 0.13 \\
\hline TTN score ${ }^{*}$ & $7(6-9)$ & $7(5-9)$ & 0.06 & $8(7-10)$ & $3(3-5)$ & 0.0000 \\
\hline $\mathrm{PH}$ & $7.28 \pm 0.14$ & $7.31 \pm 0.09$ & 0.26 & $7.26 \pm 0.13$ & $7.36 \pm 0.07$ & 0.0001 \\
\hline $\mathrm{FiO}_{2}(\%)^{*}$ & $65(50-75)$ & $60(45-75)$ & 0.06 & $65(50-80)$ & $30(25-45)$ & 0.0000 \\
\hline $\mathrm{PaO}_{2}(\mathrm{mmHg})$ & $68.04 \pm 10.03$ & $71.58 \pm 9.98$ & 0.09 & $67.69 \pm 11.19$ & $81.77 \pm 10.84$ & 0.0000 \\
\hline $\mathrm{PaCO}_{2}(\mathrm{mmHg})$ & $44.21 \pm 6.74$ & $46.17 \pm 6.42$ & 0.16 & $45.48 \pm 6.53$ & $40.33 \pm 6.76$ & 0.03 \\
\hline Serum K (mEq/L) & $4.24 \pm 0.68$ & $4.37 \pm 0.71$ & 0.38 & $4.36 \pm 0.64$ & $4.15 \pm 0.61$ & 0.07 \\
\hline Glucose (mg/dl) & $79.04 \pm 10.17$ & $77.85 \pm 9.73$ & 0.29 & $77.81 \pm 10.19$ & $80.26 \pm 9.94$ & 0.23 \\
\hline
\end{tabular}

"Median

Group I (placebo; normal saline group) and group II (treatment; salbutamol group) with a mean gestational age (36.85 $\pm 1.57 \mathrm{SD}, 36.73 \pm 1.66 \mathrm{SD})$ and a mean birth weight $(2883.15 \pm 437.94$ SD, $2825.87 \pm 414.61$ SD) respectively with no statistically significant difference. The demographic characteristics of both groups are shown in Table 2. No statistically significant differences existed between both groups in terms of gender, mode of delivery, Apgar score or maternal risk factors. The duration of respiratory support and duration of hospitalization were significantly shorter in the treatment (salbutamol) group $(P<0.0005, P<0.0002$, respectively) (Table 2 ).

Table 3 shows the means for respiratory rates, heart rates, TTN scores, $\mathrm{FiO}_{2}, \mathrm{PH}, \mathrm{PaO}_{2}, \mathrm{PaCO}_{2}$, serum $\mathrm{K}+$, and glucose in both groups before and $4 \mathrm{~h}$ after treatment. In the placebo (saline) group, there were no statistically significant differences before and after treatment in any of the aforementioned parameters. In the treatment (salbutamol) group; the respiratory rate (Fig. 1),
$\mathrm{FiO}_{2}$ (Fig. 2), and TTN score were significantly lower after treatment $(P<0.0001, P<0.0000, P<0.0000$, respectively). Also, the $\mathrm{PaO}_{2}$ significantly increased $(P<$ $0.0000)$ with significant improvement in $\mathrm{PH}(P<0.0001)$ and significant reduction in $\mathrm{PaCO}_{2}(P<0.03)$. However, there were no statistically significant differences in heart rates, serum $\mathrm{K}+$, or glucose levels after treatment.

On comparing the two groups together, before treatment, there were no statistically significant differences except for the TTN score which was higher in the salbutamol group $(P<0.01)$. After treatment, the respiratory rates, TTN score, and $\mathrm{FiO}_{2}$ were significantly lower in the salbutamol group $(P<0.0000)$. Also, there was a statistically significant difference in $\mathrm{PH}(P<0.02)$, $\mathrm{PaO}_{2}$ was significantly higher $(P<0.0000)$, and $\mathrm{PaCO}_{2}$ significantly lower $(P<0.0004)$ in the salbutamol group. No significant differences existed between the two groups after treatment as regards the heart rates, serum $\mathrm{K}+$, or blood glucose (Table 4).

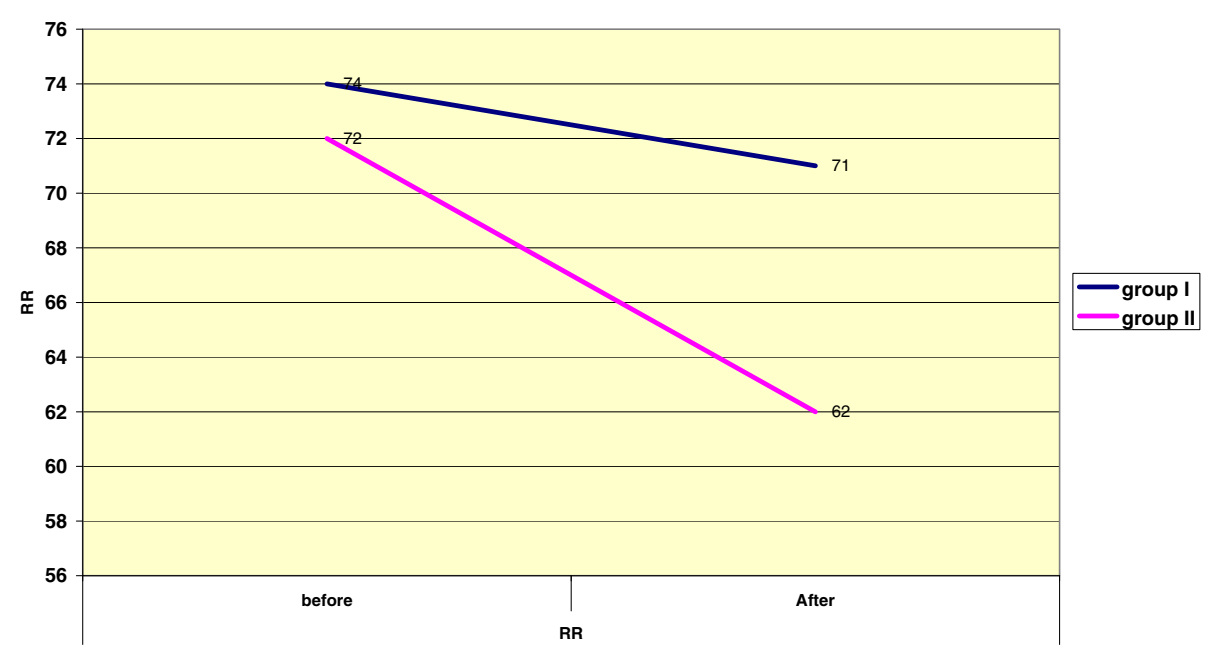

Fig. 1 Respiratory rate before and after treatment 


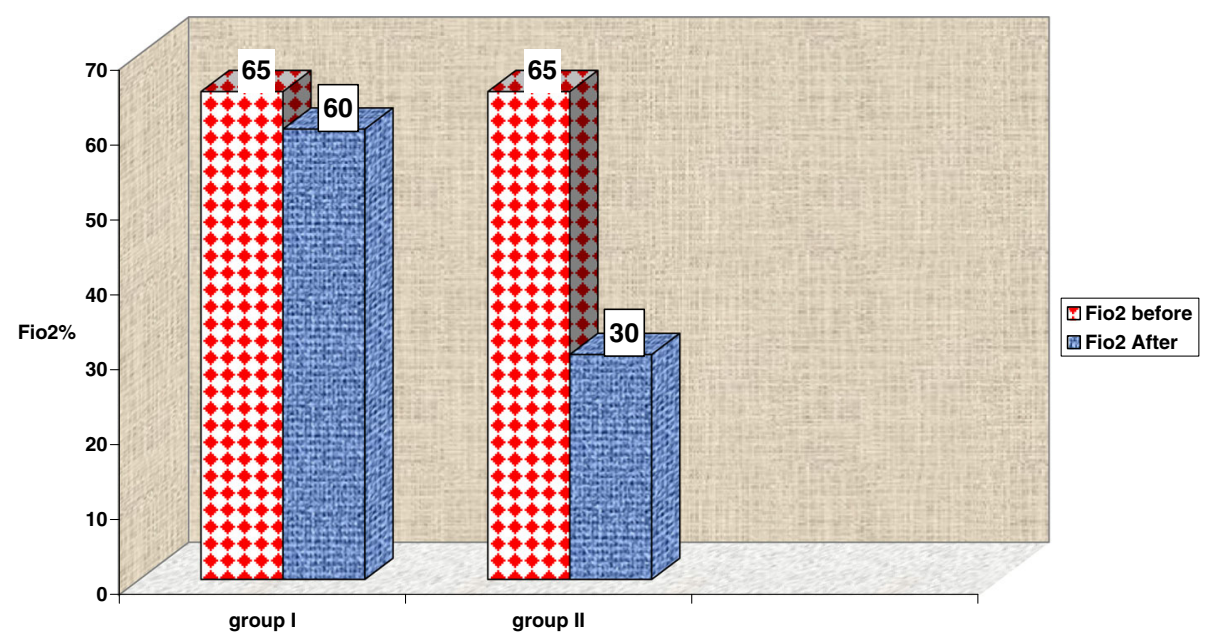

Fig. $2 \mathrm{FiO}_{2} \%$ before and after treatment

\section{Discussion}

Although a self-limited condition that presents shortly after birth and usually resolves within 48-72 $\mathrm{h}$, the tachypnea in TTN can be severe and reach 60-120 breath/min (Moresco et al. 2016). Persistent tachypnea can lead to a delay in the start of feeding, increased duration of hospitalization, and unnecessary use of antibiotics (Harding and Hooper 1996). Previously, furosemide, racemic epinephrine, and inhaled $\beta 2 A A s$ were studied to detect any potential therapeutic benefits for their use in the management of TTN; furosemide and epinephrine did not show good results, while inhaled B2AAs showed promise in some studies (Moresco et al. 2016; Kao, n.d.; Butchiboyina et al. 2017; Wiswell et al. 1985). The aim of our study was to evaluate the effect of inhaled salbutamol, a $\beta 2 \mathrm{AA}$, in management of TTN and to detect any side effects as a result of using it. In this study, the duration of respiratory support and the duration of hospitalization were significantly shorter for those treated with salbutamol than the placebo group. Mohammadzadeh et al. reported a significant shorter duration of respiratory support, hospitalization, and earlier starting of feeding in those treated with salbutamol (Mohammadzadeh et al. 2017). Also, Armangil et al. showed that salbutamol can decrease the duration of hospital stay (Armangil et al. 2011). On the other hand, Kim et al. although reporting a shorter duration of tachypnea and respiratory support, they found no significant reduction in the duration of hospitalization after salbutamol (Kim et al. 2014).

In the present study, the TTN score before treatment was significantly higher and more severe in the treatment (salbutamol) group than the placebo (saline) group, yet it significantly decreased after salbutamol treatment along with a significant reduction in the respiratory rates and $\mathrm{FiO}_{2}$ in the treatment group. Also, we found a significant rise in $\mathrm{PaO}_{2}$ with a significant improvement in $\mathrm{PH}$ and significant reduction in $\mathrm{PaCO}_{2}$ after salbutamol treatment. This is in consistence with results from other studies (Mohammadzadeh et al. 2017; Armangil et al. 2011) demonstrating that inhaled $\beta 2 \mathrm{AA}$ was found to improve clinical and laboratory parameters.

Table 4 Comparison between group I and group II before and $4 \mathrm{~h}$ after treatment

\begin{tabular}{|c|c|c|c|c|c|c|}
\hline \multirow[t]{2}{*}{ Variable } & \multicolumn{2}{|c|}{ Before treatment } & \multirow[t]{2}{*}{$P$ value } & \multicolumn{2}{|l|}{ After treatment } & \multirow[t]{2}{*}{$P$ value } \\
\hline & Group I & Group II & & Group I & Group II & \\
\hline Respiratory rate (Breath/min) & $74.36 \pm 8.08$ & $72.11 \pm 7.56$ & 0.15 & $71.47 \pm 8.15$ & $62.59 \pm 7.43$ & 0.0000 \\
\hline Heart rate (Beats/min) & $148.32 \pm 11.52$ & $144.78 \pm 10.34$ & 0.06 & $146.33 \pm 22.28$ & $142.72 \pm 10.25$ & 0.056 \\
\hline TTN Score & $7(6-9)$ & $8(7-10)$ & 0.01 & $7(5-9)$ & $3(3-5)$ & 0.0000 \\
\hline $\mathrm{PH}$ & $7.28 \pm 0.14$ & $7.26 \pm 0.13$ & 0.46 & $7.31 \pm 0.09$ & $7.36 \pm 0.07$ & 0.02 \\
\hline $\mathrm{FiO}_{2}(\%)^{*}$ & $65(50-75)$ & $65(50-80)$ & 0.84 & $60(45-75)$ & $30(25-45)$ & 0.0000 \\
\hline $\mathrm{PaO}_{2}(\mathrm{mmHg})$ & $68.04 \pm 10.03$ & $67.69 \pm 11.19$ & 0.66 & $71.58 \pm 9.98$ & $81.77 \pm 10.84$ & 0.0000 \\
\hline $\mathrm{PaCO}_{2}(\mathrm{mmHg})$ & $44.21 \pm 6.74$ & $45.48 \pm 6.53$ & 0.19 & $46.17 \pm 6.42$ & $40.33 \pm 6.76$ & 0.0004 \\
\hline Serum K (mEq/L) & $4.24 \pm 0.68$ & $4.36 \pm 0.64$ & 0.36 & $4.37 \pm 0.71$ & $4.15 \pm 0.61$ & 0.08 \\
\hline Glucose (mg/dl) & $79.04 \pm 10.17$ & $77.81 \pm 10.19$ & 0.31 & $77.85 \pm 9.73$ & $80.26 \pm 9.94$ & 0.21 \\
\hline
\end{tabular}


Similar to other studies (Mohammadzadeh et al. 2017; Armangil et al. 2011), we did not detect any side effects after salbutamol use. No significant differences existed between the two groups after treatment as regards the heart rates, serum $\mathrm{K}+$ or blood glucose.

TTN is common and can sometimes be severe leading to prolonged hospitalization and parent anxiety. The presence of therapeutic options that would decrease the time of hospitalization and save medical resources is important. However, more studies on a larger scale are required before implementing the use of inhaled $32 \mathrm{AAs}$ for routine use in TTN.

\section{Conclusion}

Inhaled salbutamol, a $\beta 2 \mathrm{AA}$, was effective in reducing the duration of respiratory support and hospitalization in TTN, with no detected side effects.

\section{Abbreviations}

ENaC: Epithelial $\mathrm{Na}$--channels; $\mathrm{FiO}_{2}$ : Fraction of inspired oxygen; K+: Potassium; Na+: Sodium; Na+-K+-ATPase: Sodium-potassium adenosine triphosphatase; NICU: Neonatal intensive care unit; $\mathrm{O}_{2}$ Sat: Blood oxygen saturation; $\mathrm{PaCO}_{2}$ : Partial pressure of arterial carbon dioxide; $\mathrm{PaO}_{2}$ : Partial pressure of arterial oxygen; TTN: Transient tachypnea of the newborn; B2AA: Beta-2 adrenergic agonist

\section{Acknowledgements}

We would like to thank the patients and their parents.

\section{Authors' contributions}

AT contributed to the idea (concept) of the study, study design, interpretation of data, and writing the manuscript and is the corresponding author. MA contributed to the collection of cases, and revised and approved the manuscript. TF contributed to the collection of cases, analysis of data, and revised and approved the manuscript. MS contributed to the collection of cases. All authors read and approved the final manuscript.

\section{Funding}

This study did not receive any financial support.

\section{Availability of data and materials}

The datasets generated during this study are available from the corresponding author on reasonable request.

\section{Ethics approval and consent to participate}

Informed consent was obtained from the parents, and the study protocol was approved by the National Research Centre Ethics Committee.

\section{Consent for publication}

Not applicable

\section{Competing interests}

The authors declare that they have no competing interests.

Received: 19 November 2019 Accepted: 13 January 2020 Published online: 21 January 2020

\section{References}

Armangil D, Yurdalock M, Korkmaz A, Yigit S, Tekinalp G (2011) Inhaled beta-2 agonist salbutamol for the treatment of transient tachypnea of the newborn. J Pediatr 159(3):398-403

Aslan E, Tutdibi E, Martens S, Han Y, Monz D, Gortner L (2008) Transient tachypnea of the newborn (TTN): a role for polymorphisms in the betaadrenergic receptor (ADRB) encoding genes? Acta Paediatr 97:1346-1350
Barker PM, Oliver PE (2002) Lung edema clearance; 20 years of progress invited review: clearance of lung liquid during the perinatal period. J Appl Physiol 93:1542-1548

Butchiboyina A, Jasani B, Deshmukh M, Patole S (2017) Strategies for managing TTN; a systemic review. J Matern Fetal Neonatal Med 30:1524-1532

Davies JC (2004) lon transport in lung disease. Pediatr Pulmonol 26:147-148

Frank JA, Wang Y, Osorio O, Matthay MA (2008) Beta-adrenergic agonist therapy accelerates the resolution of hydrostatic pulmonary edema in sheep and rats. J Appl Physiol 89:1255-1265

Harding R, Hooper SB (1996) Regulation of lung expansion and lung growth before birth. J Appl Physiol 81(1):209-224

Hjalmarson O (1981) Epidemiology and classification of acute, neonatal respiratory disorders: a prospective study. Acta Paediatr Scand 70:773-783

Kao B, Stewart de Ramirez SA, Belfort MB, Hansen A (2008) Inhaled epinephrine for the treatment of transient tachypnea of the newborn. J Perinatol 28(3): 205-210 [DOI][PubMed]

Kim MJ, Yoo JH, Jung JA, Byun SY (2014) The effects of inhaled albuterol in transient tachypnea of the newborn. Allergy Asthma Immunol Res 6(2):126-130

Minakata Y, Suzuki S, Crypgorczyk C, Dagenais A, Berthiaume Y (1998) Impact of B-adrenergic agonist on $\mathrm{Na}$ channel and $\mathrm{Na}+-\mathrm{K}+$ - ATPase expression in alveolar type 2 cells. Am J Physiol Lung Cell Mol Physiol 275:414-422

Mohammadzadeh I, Akbarian-Rad Z, Heidari F, Zahedpasha Y, HaghshenasMojaveri M (2017) The effect of inhaled salbutamol in transient tachypnea of the newborn: a randomized clinical trial. Iran J Pediatr 27(5):e9633. https:// doi.org/10.5812/ijp.9633

Moresco L, Bruschettini M, Cohen A, Gaiero A, Calevo MG (2016) Salbutamol for transient tachypnea of the newborn. Cochrane Library 5:CD0011878

Mutlu GM, Koch WJ, Factor P (2004) Alveolar epithelial beta-2-adrenergic receptors; their role in regulation of alveolar active sodium transport. Am J Respir Crit Care Med 170:1270-1275

Rawlings JS, Smith FR (1984) Transient tachypnea of the newborn: an analysis of neonatal and obstetric risk factors. Am J Dis Child 138:869-871

Richardson BS, Czikk MG, daSilva O, Natale R (2005) The impact of labor at term on measures of neonatal outcome. Am J Obstet Gynecol 192(1):219-226

Sakuma T, Folkesson HG, Suzuki S, Okanwa G, Fujimura S, Matthay MA (1997) Beta-adrenergic agonist stimulated alveolar fluid clearance in ex vivo human and rat lungs. Am J Respir Crit Care Med 155:506-512

Wiswell TE, Rawlings JS, Smith FR, Goo ED (1985) Effect of furosemide on the clinical course of transient tachypnea of the newborn. Pediatrics 75:908-910

\section{Publisher's Note}

Springer Nature remains neutral with regard to jurisdictional claims in published maps and institutional affiliations.

\section{Submit your manuscript to a SpringerOpen ${ }^{\circ}$ journal and benefit from:}

- Convenient online submission

- Rigorous peer review

- Open access: articles freely available online

- High visibility within the field

- Retaining the copyright to your article

Submit your next manuscript at $>$ springeropen.com 